August $2005 \cdot \underline{\text { Volume } 99} \cdot \underline{\text { Number } 8}$

\title{
Resolutions of ADA Title I Cases Involving People Who Are Visually I mpaired: A Comparative Analysis
}

Darlene D. Unger, Phillip D. Rumrill, Jr., and Mary L. Hennessey

Abstract: A comparison of Americans with Disabilities Act (ADA) Title I case resolutions by the Equal Employment Opportunity Commission (EEOC) involving people who are visually impaired with those involving all other people with disabilities between 1993 and 2002 revealed that people who are visually impaired are more likely than are other complainants to receive settlement benefits from their employers, to withdraw their complaints after they receive benefits without intercession from the EEOC, and to receive administrative closures. In addition, they are less likely than other complainants to have charges resolved by the issuance of a right-to-sue letter from the EEOC and to receive other closures.

In this article, we describe the pattern of case resolutions under Title I of the Americans with Disabilities Act (ADA) by the U.S. Equal Employment Opportunity Commission (EEOC) in cases involving 3,294 people who are visually impaired (that is, are blind or have low vision) and compare the pattern to that of case resolutions involving all other people with disabilities $(n=$ 186,468). Data for this investigation were obtained from the EEOC's Public Information Division, and this examination represents the universe of ADA Title I case resolutions during the 1993-2002 observation period. By understanding the disposition of ADA Title I complaints that are filed by people who are visually impaired, rehabilitation professionals can function more effectively as informed client advocates and service providers. Of 
course, this informed client advocacy should not be confused with technical legal advice, which is more appropriately the purview of attorneys and other specialists, but a strong working knowledge of the EEOC's procedures and outcomes can enhance career counseling, vocational planning, and job placement efforts on behalf of people who are visually impaired.

\section{Employment concerns of Americans who are visually impaired}

Despite progressive laws that are designed to break down barriers to employment for people with disabilities and the proliferation of workplace supports provided by both employers and rehabilitation professionals, the labor force participation of people who are visually impaired and of working age (16-69 years) continues to lag far behind that of the general population. For instance, the reported employment rate for working-age people who are visually impaired is approximately 45\%, compared to 74\% for sighted people who are of working age (U.S. Department of Labor, 2004). Furthermore, many employees who are visually impaired have reported that they are underemployed (Giesen et al., 1985; Kirchner, Schmeidler, \& Todorov, 1999; Rumrill, Schuyler, \& Longden, 1997). The average monthly pay of workers who are visually impaired is $37 \%$ lower than that of people who are not disabled (McNeil, 1993).

The difficulties that people who are visually impaired encounter in seeking, obtaining, and maintaining employment have been well documented in the rehabilitation literature. These challenges include unfair hiring practices (Crudden, McBroom, Skinner, \& Moore, 1998; McMahon, Jaet, \& Shaw, 1995; Rumrill \& Scheff, 1997; Tedder \& McBroom, 1989), negative attitudes by employers (Berry \& Meyer, 1995; Crudden et al., 1998; Frank, 2003; Kirchner, Johnson, \& Harkins, 1997), the lack of availability of transportation to the work site (Crudden et al., 
1998; Frank, 2003; Kirchner, Harkins, \& Esposito, 1991; Rumrill et al., 1997), and difficulty locating information about potential jobs (Crudden et al., 1998). They also include the inability to read printed material (Crudden et al., 1998; Frank, 2003), difficulty identifying and obtaining accommodations for acquiring and performing jobs (Crudden et al., 1998; Frank, 2003; McMahon et al., 1995), and alienation and resistance from coworkers (Crudden \& Fireson, 1997; Frank, 2003; Lee, 1996).

Rehabilitation counselors and employers play a pivotal role in supporting job seekers and employees with visual impairments in overcoming many of these challenges to labor force participation. However, individuals who are visually impaired, rehabilitation professionals, and employers generally do not understand the requirements of Title I of the ADA (Frank, 2003; Rumrill, 1999). Employers have specifically acknowledged their limited knowledge of the ADA's employment regulations, even though they have expressed their increased awareness and acceptance of the law (Curry, 1996; Lewis, 1997). For their part, people who are visually impaired (and those with other disabilities, for that matter) may not be well informed about the ADA (National Organization on Disabilities, 2002), the types of accommodations that are available to address their need for support (Leitman, Binns, \& Risher, 1995; Unger, 2001), or how to go about obtaining needed workplace supports (Rumrill, 2001; Sacks, 1997). Unfortunately, the inability of all stakeholders in the employment process to identify, address, and resolve the barriers to employment experienced by visually impaired individuals may lead to allegations of employment discrimination.

Without question, discrimination is a significant barrier to attempts by people who are visually impaired to acquire and retain employment (Crudden et al, 1998; McMahon et al., 1995; Moss, Ranney, \& Gunther-Mohr, 2000; Rumrill, Roessler, Battersby-Longden, \& Schuyler, 1998; Rumrill \& Scheff, 1997; 
Tedder \& McBroom, 1989). An investigation of the types of allegations of employment discrimination that were filed with the EEOC indicated that visually impaired individuals had the second highest proportion of complaints involved in hiring (17\%), behind only those with physical disfigurements (17.6\%; McMahon et al., 1995). These rates were substantially higher than those for persons with less-conspicuous disabilities. This finding is not surprising, given that when employers reported that they changed their recruitment, preemployment screening, testing, and orientation procedures to comply with the ADA, they noted that they had the greatest difficulty making information accessible to people with visual or learning impairments (Society for Human Resource Management, 1999). People who were visually impaired also encountered other forms of discrimination when they applied for jobs, such as employers' refusal to provide readers for job applications and for preemployment tests, even when advance notice was provided (Frank, 2003).

Much more common among people who are visually impaired have been allegations of discrimination that is related to job retention. Specifically, current visually impaired employees filed ADA Title I complaints involving unlawful termination (28\%), failure to provide reasonable accommodations (17\%), disability harassment (5\%), promotion (4\%), discipline (4\%), layoffs (3\%), wages (2\%), benefits (2\%), suspension (1\%), and other issues that were related to the maintenance and advancement of their careers (17\%; McMahon et al., 1995). These data suggest that persons who are visually impaired encounter discrimination in every aspect of career development and that the ADA has been more effective in bringing employment discrimination to light than in decreasing its incidence (Schall, 1998).

Several studies have documented the perceptions or allegations of people who are visually impaired about employment discrimination, but less is known about the outcomes of these 
allegations. Therefore, this study examined the manner in which the EEOC resolves complaints of employment discrimination under the ADA by people who are visually impaired, both in absolute terms and in comparison to case-resolution practices concerning all other ADA Title I complainants. Specifically, we examined the pattern of ADA Title I case resolutions involving people who are visually impaired across seven main categories of resolution and then empirically compared that pattern to the universe of all ADA Title I case resolutions involving people with other disabilities.

\section{Method}

We requested and retrieved data on resolutions of complaints of employment discrimination involving people who are visually impaired from the EEOC's Office of Information Resources Management, Charge Data System Division. We then calculated descriptive statistics, primarily frequencies and percentages, for both groups of complainants (complainants who are visually impaired and complainants with all other disabilities) across the seven derived categories of case resolutions that were reported by the EEOC: settlements, withdrawal with benefits, reasonable cause, no reasonable cause, notice of a right-to-sue request, administrative closure, and other. A chi-square analysis was conducted to determine if there were any statistically significant differences between the pattern of complaint resolutions involving the two groups during a 10-year period (1993-2002).

\section{Description of the database}

The EEOC's Charge Data System is a national database that provides a charge-receipt listing of all federal discrimination complaints that were filed in accordance with Title I of the ADA or any other civil rights law providing employment coverage to protected classes (such as Title VII of the Civil Rights Act and the 
Age Discrimination in Employment Act). It also tracks the steps that the EEOC takes to investigate and resolve complaints. The database lists complaint resolutions by type; we collapsed all resolutions during 1993-2002 into seven mutually exclusive categories (listed earlier).

In terms of the operational definitions of the collapsed categories, a settlement is a case in which the EEOC negotiates a settlement with benefits to the charging party, as warranted by evidence that was presented in the complaint. Withdrawal with benefits refers to complaints that are withdrawn by the charging party after he or she receives benefits from the employer. Reasonable cause means that the EEOC determines, upon investigation, that discrimination occurred against the charging party; this finding leads to formal efforts by the EEOC to conciliate the claim, and, for the purposes of our study, this category includes both successful and unsuccessful attempts at conciliation. No reasonable cause means that the EEOC determines that the complaint lacks grounds for a charge of discrimination; this finding does not prevent the charging party from pursuing a private court action. Notice of $a$ right-to-sue request occurs when the EEOC issues a right-to-sue letter to the charging party without making any other determinations or negotiating any settlements. The right-to-sue letter informs the charging party that the EEOC did not make a formal finding in the matter and that the charging party has the right to pursue further legal action in Federal Circuit Court. Notice of right-to-sue request is the category heading that the EEOC uses for cases that are resolved via the right-to-sue letter. For this article, notice of right-to-sue request and right-to-sue letter are one and the same. Administrative closures occur when the charging party cannot be located during the investigation, the charging party fails to respond to EEOC communications, full relief is refused by the charging party, related litigation interferes with the EEOC's ability to render a determination, the charging party withdraws the claim without receiving benefits or reaching 
a resolution, the employer files for bankruptcy while the claim is being investigated, or the EEOC does not have statutory jurisdiction. The other category is undefined in the EEOC's publicly available regulations.

The database identifies 17 categories of types of disabilities into which complainants are categorized. For the purpose of this investigation, all types of disabilities except visual impairment were collapsed into one category to allow for comparisons between the proportions of case resolutions involving people who are visually impaired and the proportions of case resolutions involving people with all other disabling conditions.

Upon our request, the EEOC retrieved from its database an analysis of all complaint resolutions under Title I of the ADA for each fiscal year from 1993 to 2002. Analyses were conducted and descriptively reported by the EEOC in response to requests for aggregate data describing ADA Title I complaint resolutions, according to the type of resolution, involving people who are visually impaired and those involving all people with disabilities except those who are visually impaired.

\section{Limitations of the database}

Demographic information (other than type of disability) that pertains to individuals who filed complaints with the EEOC is not publicly available. Thus, it is not possible to conduct analyses on the basis of variables that have been linked in previous research to the likelihood that one may exit the workforce for disabilityrelated reasons (such as gender, age, and educational attainment).

\section{Results}

The results of this investigation are presented in two parts. The first part consists of descriptive statistics (frequencies and 
percentages) on the types of ADA Title I complaint resolutions involving people who are visually impaired and people with other disabilities during the observation period (1993-2002). The second part presents the results of a nonparametric comparison of case-resolution patterns involving the two referent groups.

Table 1 presents the frequencies and percentages of ADA Title 1 complaint resolutions for the seven derived categories for both groups. Between 1993 and 2002, the EEOC resolved a total of 189,762 Title I complaints, of which 3,294 involved people who are visually impaired and 186,468 involved people with other disabling conditions. As is evident in Table 1, for people who are visually impaired, $51.85 \%$ of the ADA Title I complaints that were filed during the observation period were dismissed as groundless (no reasonable cause) by the EEOC at the first level of administrative review, and $14.30 \%$ cases resulted in administrative closures. The remainder of the cases involving people who are visually impaired were resolved in the following ways: notice of a right-to-sue request (11.14\%), settlements (9.44\%), reasonable cause (6.71\%), withdrawal with benefits (6.44\%), and other (0.12\%).

Similarly, the majority (54.02\%) of all other ADA Title I complainants received findings of no reasonable cause from the EEOC during the 10-year study period. The second-mostcommon resolution for this group was the EEOC's issuance of a right-to-sue letter (17.16\%), followed by administrative closure (10.02\%), reasonable cause (6.31\%), settlements (6.22\%), withdrawal with benefits (4.86\%), and other (1.42\%).

The causal comparative aspect of this study involved a nonparametric (chi-square) analysis of the differences in case resolutions involving complainants who are visually impaired and all other complainants. Specifically, the chi-square analysis revealed a significant overall difference between the two groups 
in the proportions of case resolutions reported by the EEOC across the seven derived categories of resolution $(X 2[6, N=$ $189,762]=240.13, p<.001)$.

Given the overall significant difference, a standardized residual was computed for each of the seven resolution categories to determine the major contributors to the overall test of significance. The results indicated that five of the seven categories were major contributors - settlements, withdrawal with benefits, notice of a right-to-sue request, administrative closure, and other. More specifically, people who are visually impaired were significantly more likely than were all other complainants to receive settlements, to withdraw their complaints with benefits, and to receive administrative closures and were less likely to be issued a right-to-sue letter and to receive other types of closures. There were no differences between the two groups in the proportions of reasonable cause and no reasonable cause resolutions.

\section{Discussion}

Even though the pattern of ADA Title I case resolutions for people who are visually impaired is significantly different from that of all other ADA Title I complainants, the comparative aspects of this study may not bear the most compelling findings. Rather, viewing the pattern of ADA Title I case resolutions involving people who are visually impaired in absolute terms illuminates what are perhaps the most salient implications for rehabilitation practice and future research.

For example, the majority (51.85\%) of Title I complaints by people who are visually impaired between 1993 and 2002 were dismissed by the EEOC after a finding of no reasonable cause, and $14.3 \%$ were closed by the EEOC for administrative reasons, usually because the charging party failed to follow through in 
assisting the EEOC to investigate the claim. Roughly stated, approximately two-thirds of the ADA Title I complaints involving people who are visually impaired were either dismissed as groundless or closed without a finding because the investigation could not be completed. These findings clearly call for improved information and technical assistance to aid people who are visually impaired in redressing perceived discrimination in employment. Visually impaired people need to know what their rights are under Title I of the ADA, the limitations of their civil rights protections under the law, and procedures for participating in the EEOC's complaint-and-resolution process.

Rumrill (1999) noted that visually impaired workers often lack adequate knowledge of the ADA and other employment-related laws. To reduce the incidence of groundless complaints, people who are visually impaired need up-to-date information in accessible formats regarding their legal rights as current or prospective workers. McMahon and Domer (1997) presented an example of the straightforward legal descriptions that people with visual impairments need in their side-by-side comparison of the ADA, the Family and Medical Leave Act, and state workers' compensation statutes. A similar and updated document could be targeted toward workers with visual impairments and rehabilitation professionals — one that clearly specifies the standards that the EEOC applies in determining the legitimacy of Title I complaints. Issues addressed in this informational guide could include the disclosure of disability status, procedures for requesting reasonable accommodations, time frames for making complaints to the EEOC, remedies under Title I, and the mitigating-measures standard in the 2002 Sutton Supreme Court decision (Frank, 2003).

Once they understand the extent and limitations of their ADA Title I protections, people who are visually impaired need to be advised to consider making a formal discrimination complaint 
only as a last resort, after nonadversarial problem-solving strategies have been exhausted. A formal action against one's employer has the effect of permanently altering the employeeemployer relationship (Sumner, 1995); takes months and sometimes years to resolve (McMahon et al., 1995; Moss, Burris, Ullman, Johnsen, \& Swanson, 2001); and, judging from the findings presented here, usually does not result in a resolution that is in favor of the complainant. Therefore, strategies for resolving potential work-related issues before they progress to the point of perceived discrimination and a formal complaint must be emphasized in career planning and vocational rehabilitation efforts on behalf of people with visual impairments.

Roessler and Rumrill (2004) developed the "win-win approach to reasonable accommodations" as a means of helping employees with chronic illnesses retain employment without engaging in costly and counterproductive litigation against their employers. This guide could be easily adapted for people who are visually impaired. It features a collaborative process whereby employees and employers work together to identify, implement, and evaluate the ongoing effectiveness of disability-related accommodations in a manner that is consistent with the provisions of Title I of the ADA. However, as the term win-win implies, strong emphasis is placed on formally invoking the ADA only in cases in which the collaborative dialogue between the employee and employer breaks down. For such cases, clear guidance is offered on how to document claims of discrimination in a manner that gives the complainant the best chance to prevail in the EEOC's complaintresolution process.

Of course, asserting one's civil rights in a fashion that is viewed by the employer as nonadversarial requires considerable selfadvocacy skills. Rumrill (1999) demonstrated the effectiveness of a social competence training program to train people who are visually impaired to request on-the-job accommodations from 
their employers. The program included specific training on the ADA's Title I requirements, a structured interview in which the participants identified their most prominent disability-related concerns, and role-playing in which the participants rehearsed the conversations they intended to have with their employers to address their on-the-job needs in a nonadversarial fashion. At a 16-week follow-up, the participants who received the intervention reported higher mean levels of knowledge of the ADA, higher mean levels of self-efficacy in invoking their employment rights, and a higher rate of successful on-the-job accommodations than did a matched control group of visually impaired employees who did not receive the intervention.

The causal comparative aspect of this study provides some evidence that people who are visually impaired may already possess some of the self-advocacy skills that they need to invoke their rights to nondiscriminatory employment practices, at least in comparison to people with disabilities in general. The fact that people who are visually impaired are more likely than are all other ADA Title I complainants to receive settlement benefits from the EEOC and to withdraw their complaints after they receive benefits from their employers could be explained by more effective self-advocacy skills. However, the higher rate of benefit resolutions may also be explained by differences in the type of discrimination that people who are visually impaired experience in comparison to people with other disabilities. It may be that the discrimination faced by people with visual impairments is more conspicuous or more job- threatening than is the discrimination faced by people with other disabilities, so when a person who is visually impaired makes a formal complaint to the EEOC, he or she is more likely to receive benefits. This phenomenon could be better understood through research on the types of discrimination that are alleged by people with visual impairments in ADA Title I complaints, and these data can be accessed through the same EEOC database that we used in this study. 
Future researchers should also consider using more specific comparison groups than the "all-or-nothing" dichotomy that we used in this study. For example, comparing people who are visually impaired to people with other sensory disabilities, to people with physical disabilities, to people with cognitive impairments, and to people with chronic illnesses (such as diabetes) that commonly result in visual impairment would provide a more sensitive frame of reference through which to examine EEOC case resolutions involving this population. Another extension of this study would be to examine caseresolution patterns along a time-series dimension, perhaps before and after the 1999 Sutton Supreme Court decision that substantially narrowed the definition of disability under Title I of the ADA. Understanding how case-resolution patterns have changed over time for the now-15-year-old ADA would provide some historical context for the employment discrimination experiences of people who are visually impaired.

Certainly, no attempt to address the issue of employment discrimination can be effective if it excludes employers' perspectives as a key variable. Research on employers' attitudes has found that employers are generally favorably inclined to hire people who are visually impaired, especially in comparison to workers with psychiatric disabilities and mental retardation (Unger, 2001). However, a closer examination of employers' attitudes reveals that employers have a number of specific concerns regarding workers who are visually impaired, including the cost of assistive devices; transportation; safety; secondary complications of illnesses, such as diabetes; and discomfort by other workers and customers (Gilbride, Stensrud, Ehlers, Evans, \& Peterson, 2000; Society for Human Resource Management, 1999). Educating employers about assistive technology, public transportation, and the medical aspects of visual impairment could certainly alleviate some of those concerns, but the most 
powerful antidote to employers' negative attitudes is direct experience working with people with disabilities (Kregel \& Unger, 1993; Unger \& Kregel, 2003). To facilitate such an experience, rehabilitation professionals must consult with employers to identify strategies to accommodate workers who are visually impaired, resolve disability-related issues in a nonadversarial fashion, help employers interpret and meet their legal obligations under Title I of the ADA and other legislation, and refer prospective employees who have the career maturity and technical skills to succeed in an increasingly competitive American workplace (Jenkins \& Strauser, 1999; Rumrill, 1999; Sumner, 1995).

\section{Conclusion}

The barriers that confront visually impaired Americans who attempt to find and maintain employment have been well documented in previous research. Employers' negative attitudes and lack of knowledge of the ADA and workplace supports are factors that contribute to the career development difficulties experienced by individuals with visual impairments and ultimately lead to alleged employment discrimination. How the EEOC resolves discrimination complaints on behalf of people who are visually impaired is an important aspect of the discrimination experienced by people with visual impairments. The findings of this study indicate that people who are visually impaired are more likely than are other ADA Title I complainants to be awarded settlement benefits from the EEOC, to withdraw their complaints after they receive benefits from their employers, and to have their complaints resolved administratively without directional findings, and are less likely to receive a right-to-sue letter and other closures. By understanding the case outcomes that people with visual impairments are likely to encounter after they file formal ADA Title I complaints with the EEOC, rehabilitation 
professionals can serve as more effective client advocates by promoting nonadversarial problem solving that includes making formal complaints as a last resort when no other resolution can be reached.

\section{References}

Berry, J. O., \& Meyer, J. A. (1995). Employing people with disabilities: Impact on attitudes and situation. Rehabilitation Psychology, 40, 211-222.

Crudden, A., \& Fireson, C. (1997). Employment retention after vision loss: Intensive case studies. Mississippi State:

Rehabilitation Research and Training Center on Blindness and Low Vision, Mississippi State University.

Crudden, A., McBroom, L. W., Skinner, A. L., \& Moore, J. E. (1998). Comprehensive examination of barriers to employment among persons who are blind or visually impaired (technical report). Mississippi State: Rehabilitation Research and Training Center on Blindness and Low Vision, Mississippi State University.

Curry, D. A. (1996). Employers' perceptions of the Americans with Disabilities Act and its effects on vertical mobility in the business world (Doctoral dissertation, University of Rochester, 1996). Dissertation Abstracts International, 57-05A, 2185.

Frank, J. J. (2003). The impact of the Americans with Disabilities Act (ADA) on the employment of individuals who are blind or have severe visual impairments. Part I: Elements of the ADA accommodation request process. Mississippi State: Rehabilitation Research and Training Center on Blindness and Low Vision, Mississippi State University. 
Giesen, J. M., Graves, W. M., Schmitt, S., Lamb, A. M., Capps, C., \& Boyd, K. (1985). Predicting work status outcomes of blind/ severely visually impaired clients of state rehabilitation agencies. Mississippi State: Rehabilitation Research and Training Center on Blindness and Low Vision, Mississippi State University.

Gilbride, D. D., Stensrud, R., Ehlers, C., Evans, E., \& Peterson, C. (2000). Employers' attitudes towards hiring persons with disabilities and vocational rehabilitation services. Journal of Rehabilitation, 66(4), 17-24.

Jenkins, W., \& Strauser, D. (1999). Horizontal expansion of the role of the rehabilitation counselor. Journal of Rehabilitation, 65 (1), 4-9.

Kirchner, C., Harkins, D., \& Esposito, R. (1991). Issues and strategies toward improving employment of blind or visually impaired persons in Illinois. Unpublished study report, American Foundation for the Blind.

Kirchner, C., Johnson, G., \& Harkins, D. (1997). Research to improve vocational rehabilitation: Employment barriers and strategies for clients who are blind or visually impaired. Journal of Visual Impairment \& Blindness, 91, 377-392.

Kirchner, C., Schmeidler E., \& Todorov, A., (1999). Looking at employment through a lifespan telescope: Age, health and employment status of people with serious visual impairment. Mississippi State: Rehabilitation Research and Training Center on Blindness and Low Vision, Mississippi State University.

Kregel, J., \& Unger, D. (1993). Employer perceptions of the work potential of individuals with disabilities: An illustration from supported employment. Journal of Vocational 
Rehabilitation, 3(4), 17-25.

Lee, B. (1996). Legal responsibilities and employer resources to accommodating employees with disabilities. Human Resource Management Review, 6, 231-251.

Leitman, R., Binns, K., \& Risher, P. (1995). The Lighthouse national survey on vision loss: The experience, attitudes and knowledge of middle-aged and older Americans. New York: The Lighthouse.

Lewis, N. V. (1997). Assessing employers' understanding of the employment provisions of the Americans with Disabilities Act. Unpublished doctoral dissertation, Oklahoma State University.

McMahon, B., \& Domer, T. (1997). 20 questions surrounding unpaid medical leave: Navigating the Bermuda triangle of employment law. Work, 9, 129-145.

McMahon, B. T., Jaet, D. N., \& Shaw, L. R. (1995). An empirical analysis: Employment and disability from an ADA litigation perspective. NARPPS Journal, 10(1), 3-14.

McNeil, J. M. (1993). Americans with disabilities: 1991-1992, current population reports, pp. 33-70. Washington, DC: U.S. Government Printing Office.

Moss, K., Burris, S., Ullman, M., Johnsen, M., \& Swanson, J. (2001). Unfunded mandate: An empirical study of the implementation of the Americans with Disabilities Act by the Equal Employment Opportunity Commission. Kansas Law Review, 50(1), 1-110.

Moss, K., Ranney, L., \& Gunther-Mohr, C. (2000). The ADA and you: What to do when an employer discriminates against you because of your disability. Chapel Hill, NC: Cecil G. Sheps 
Center for Health Services Research, University of North Carolina.

National Organization on Disabilities and Louis Harris \& Associates. (2002). The N.O.D./Harris Survey Program on Participation and Attitudes: Survey of Americans with Disabilities. New York: Author.

Roessler, R., \& Rumrill, P. (2004). Enhancing productivity on your job: The win-win approach to reasonable accommodations. New York: National Multiple Sclerosis Society.

Rumrill, P. (1999). Effects of a social competence training program on accommodation request activity, situational selfefficacy, and Americans with Disabilities Act knowledge among employed people with visual impairments and blindness. Journal of Vocational Rehabilitation, 12(1), 25-31.

Rumrill, P. (2001). Reasonable accommodations and the Americans with Disabilities Act: It's all about communication. Journal of Vocational Rehabilitation, 16(3-4), 235-240.

Rumrill, P. D., Roessler, R. T., Battersby-Longden, J. C., \& Schuyler, B. R. (1998). Situational assessment of the accommodation needs of employees who are visually impaired. Journal of Visual Impairment \& Blindness, 92, 42-54.

Rumrill, P. D., \& Scheff, C. M. (1997). Increasing participation in the accommodations process among persons with visual impairments and blindness: A call to action in the ADA era. Journal of Visual Impairment \& Blindness, 91, 460-466.

Rumrill, P. D., Schuyler, J. C., \& Longden, J. C. (1997). Profiles of on-the-job accommodations needed by professional employees who are blind. Journal of Visual Impairment \& 
Blindness, 91, 66-76.

Sacks, S. (1997). Psychological and social implications of low vision. In A. Corn \& A. Koenig (Eds.), Foundations of low vision: Clinical and functional perspectives (pp. 26-42). New York: AFB Press.

Schall, C. (1998). The Americans with Disabilities Act-Are we keeping our promise? An analysis of the effect of the ADA on the employment of persons with disabilities. Journal of Vocational Rehabilitation, 10, 191-204.

Society for Human Resource Management/Cornell University. (1999, March). The ADA at work: Implementation of the employment provisions of the ADA. Ithaca, NY: Author.

Sumner, G. (1995). Project Alliance: A job retention program for people with chronic illness and their employers. New York: National Multiple Sclerosis Society.

Tedder, N. E., \& McBroom, L. W. (1989). Career transition of professionally employed adults with visual disabilities: Policy implications and recommendations for practitioners. Mississippi State: Rehabilitation Research and Training Center on Blindness and Low Vision, Mississippi State University.

Unger, D. (2001). Employers' attitudes toward persons with disabilities in the workforce: Myths or realities? Focus on Autism and Other Developmental Disabilities, 16(1), 67-75.

Unger, D., \& Kregel, J. (2003). Employers' knowledge and utilization of accommodations. Work, 21(1), 5-16.

U.S. Department of Labor, Bureau of Employment Statistics (2004). Occupational Outlook Handbook (Electronic Resource). Washington, DC: Author. 
Darlene D. Unger, Ph.D., assistant professor, Rehabilitation Research and Training Center on Workplace Supports and Job Retention, Virginia Commonwealth University, 1314 West Main Street, Richmond,VA 23284; e-mail: < ddunger@vcu.edu>.

Phillip D. Rumrill, Jr., Ph.D., professor, Department of Educational Foundations and Special Services, Center for Disability Studies, Kent State University, P.O. Box 5190, Kent, OH 44242-0001; e-mail: <prumrill@kent.edu>. Mary L.

Hennessey, Ph.D., research associate, Department of Educational Foundations and Special Services, Center for Disability Studies, Kent State University; e-mail: <mlhennes@kent.edu >.

\section{$\underline{\text { Previous Article } \mid \text { Next Article } \mid \text { Table of Contents }}$}

JVIB, Copyright @ 2005 American Foundation for the Blind. All rights reserved.

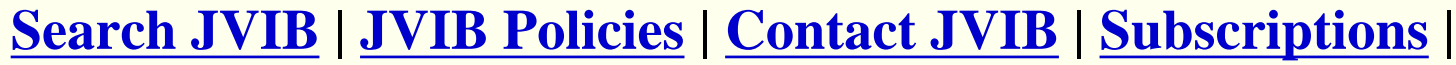 JVIB Home}

If you would like to give us feedback, please contact us at jvib@afb.net. 


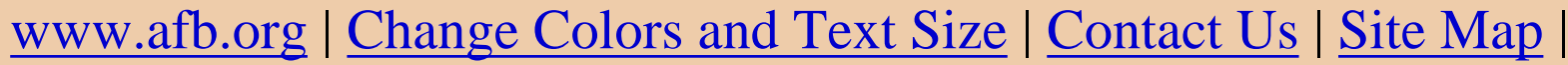 Site Search $\longrightarrow$ Go

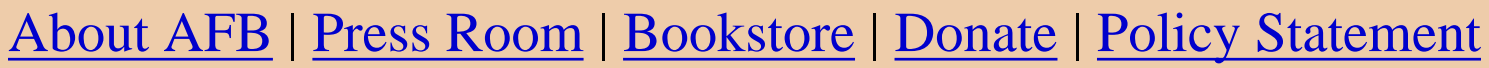

Please direct your comments and suggestions to afbinfo@afb.net Copyright $(\mathbb{C} 2005$ American Foundation for the Blind. All rights reserved. 